\title{
BCCN4
}

\section{IMPACT BEHAVIOR OF GLARETM HYBRID LAMINATE UNDER EXTREME THERMAL CONDITIONS}

\author{
Francisco J. Goyo-Brito, Matheus Vogler, Richard F. Silva, Alessandra C. Soares-Pozzi, \\ José R. Tarpani*
}

Sao Carlos School of Engineering (EESC-USP), 13.566-590, Sao Carlos-SP, Brazil

*Corresponding author: jrpan@sc.usp.br

https://doi.org/10.21452/bccm4.2018.07.05

\begin{abstract}
Artificial bodies intentionally placed into low orbit around the earth (LEO) are exposed to critical thermal and mechanical in-service conditions, e.g. severe thermal cycling and micrometeoroid impact. To better understand the response of Glare ${ }^{\mathrm{TM}}-5$ 2/1 fiber-metal laminate under such conditions, pristine test coupons were subjected to low-energy ballistic impact ( $21 \mathrm{~J}$ ) at the temperatures of -196 and $100{ }^{\circ} \mathrm{C}$. Another set of test pieces went through the same experimental conditions, except that they were first submitted to 1,200 thermal shock cycles from -196 to $100{ }^{\circ} \mathrm{C}$. Thermally conditioned specimens exhibited higher resistance to externally visible damage in both test temperatures. On the other hand, internal failure mechanisms characterized via microscopy and X-ray CT inspection techniques have shown that specimens submitted to cryogenic impact after repeated thermal cycling presented the best impact resistance, being age hardening of outer 2024-T3 Al-alloy sheets a possible enhancing factor; besides, residual thermal stresses in the core glass fiber-reinforced epoxy matrix, associated to the post-cure of the latter may have led to higher interlaminar strength.
\end{abstract}

Keywords: Glare ${ }^{\mathrm{TM}}$ fiber metal-laminate; LEO extreme temperatures; low-energy ballistic impact, repeated thermal shock.

\section{INTRODUCTION}

Composites materials has increased their popularity in several application fields, especially in the construction of aeronautic and astronautic structures. They are preferred structural materials over traditional metallic alloys since they exhibit extraordinary structural efficiency, which means outstanding weight savings potential.

Fiber metal laminates (FML) are an especial class of composite materials, where alternating metal sheets and fiber-reinforced polymer (FRP) layers are bonded together, thus combining the great impact toughness of the former and the high fatigue resistance of the latter [1,2]. Glass Reinforced-Fiber Metal Laminate (Glare ${ }^{\mathrm{TM}}$ ), comprising glass fiberreinforced epoxy resin layers and high strength 2024-T3 Al-alloy sheets, is the greatest exponent of FML to date [3]. E.g., it has been chosen to serve as skin material in fuselage 
sections $\left(500 \mathrm{~m}^{2}\right)$ of the Airbus A380, which means approximately 1 ton. of weight saving, corresponding to approximately 4 additional passengers [4].

The excellent performance of Glare ${ }^{\mathrm{TM}}$ in the aeronautical sector naturally led to expectations about its use in astronautic structures.

Satellites and spacecrafts orbiting around the earth are exposed to quite extreme temperature changes as they pass from earth shadow to direct sun radiation, leading to variations ranging from -190 to $+120^{\circ} \mathrm{C}$, not to mention micrometeoroid particles' hyper-velocity impacts [5-8].

So far, to the best of our knowledge, there is no information regarding the impact behavior of Glare $^{\mathrm{TM}}$ after withstanding extreme thermal cycles (i.e., repeated thermal shock conditions), as to simulate low orbit environment conditions.

In this work, the effect of multiple thermal shocks on the impact behavior of Glare ${ }^{\mathrm{TM}}$ laminate tested at extreme temperatures has been assessed. Internal failure mechanisms were characterized via optical and scanning electron microscopies and X-ray CT inspection, while thermal analysis, infrared spectroscopy, transmission electron microscopy, and nano- and micro-hardness techniques, besides three-point bend testing were employed to disclose the root causes of the observed performances of Glare ${ }^{\mathrm{TM}}$ under different pre-conditioning treatments and impact testing temperatures.

\section{MATERIAL AND PROCEDURES}

\subsection{Material}

1.6 mm-thick Glare ${ }^{\mathrm{TM}} 5$ 2/1 FML, consisting of two outer sheets of 2024-T3 Al-alloy and one inner S2 glass fibers/epoxy matrix laminate built according to the stacking sequence $[0 / 90]_{s}$, was used. Full-thickness samples and test pieces were cut from a 200 x $300 \mathrm{~mm}^{2}$ plate supplied by Comtek Advances Structures ${ }^{\mathrm{TM}}$ - Canada. A bench saw using a water-cooled diamond disc was utilized for this purpose.

\subsection{Thermal shock cycling (TSC)}

Samples and test specimens were previously exposed to TSC treatment $(1,200$ cycles in total) between extreme temperatures, namely -196 and $+100{ }^{\circ} \mathrm{C}$. The lowest temperature was achieved in liquid nitrogen $\left(\mathrm{L}_{2} \mathrm{~N}\right)$, whereas the highest one in boiling water. Soaking time was 15 minutes for both liquid media.

\subsection{Thermogravimetry analysis (TG)}

Thermal stability of the glass fiber-reinforced epoxy resin (FRP - fiber-reinforce polymer) core of Glare ${ }^{\mathrm{TM}}$ in the as-received and TSC conditions was determined via Perkin Elmer ${ }^{\mathrm{TM}}$ analyzer model Pyris 1 . TG scans were performed at $10^{\circ} \mathrm{C} / \mathrm{min}$ in the temperature range from $30{ }^{\circ} \mathrm{C}$ to $700{ }^{\circ} \mathrm{C}$. $\mathrm{N}_{2}$ atmosphere was used.

\subsection{Fourier-transform infrared spectroscopy (FTIR)}

FTIR spectra of Glare's epoxy resin matrix in both pristine and TSC conditions were acquired in Perkin-Elmer ${ }^{\mathrm{TM}}$ model Spectrum 100 spectrophotometer. Wavelength range from 4000 to $600 \mathrm{~cm}^{-1}$ was swept at a resolution of $4 \mathrm{~cm}^{-1}$. Attenuated total reflectance method (ATR) technique was employed.

\subsection{Dynamic mechanical analysis (DMA)}

DMA of Glare ${ }^{\mathrm{TM}}$ hybrid composite in the as-manufactured and TSC conditions were performed in Perkim Elmer ${ }^{\mathrm{TM}}$ model DMA 8000 to determine thermomechanical properties, 
namely, storage modulus (E'), loss modulus (E"), damping factor (tan $\delta$ ) and glass transition temperature $\left(\mathrm{T}_{\mathrm{g}}\right)$. The experiments were carried out in specimens with in-plane dimensions of $50 \times 10 \mathrm{~mm}^{2}$ tested in dual cantilever loading mode at a frequency of $1 \mathrm{~Hz}$. Temperature ramp was $2{ }^{\circ} \mathrm{C} / \mathrm{min}$ for a swept temperature range from 30 to $300^{\circ} \mathrm{C}$. $\mathrm{T}_{\mathrm{g}}$ was determined from the peak of the $\tan \delta$ curve.

\subsection{Low-energy ballistic impact testing (LBT)}

Square specimens with in-plane dimensions of $50 \times 50 \mathrm{~mm}^{2}$ were firmly clamped in a stainless-steel frame with a $45 \times 45 \mathrm{~mm}^{2}$ window, which was tightly fastened to a thin 2024 Al-alloy panel $\left(2 \times 1,75 \times 1.6 \mathrm{~mm}^{3}\right)$ to simulate a repaired aircraft skin-substructure. LBT of as-fabricated and TSC conditions was performed with 5.5 caliber air-gun shooting cast lead bullets weighting $1.6 \mathrm{~g}$. All specimens were centrally impacted at a bullet speed of $230 \mathrm{~m} / \mathrm{s}$. Considering the gun tip-to-specimen target distance of $15 \mathrm{~cm}$ and an impact angle of $45^{\circ}, 21 \mathrm{~J}$ was estimated as the energy apportion to the FML test pieces. Test temperatures were -196 and $+100{ }^{\circ} \mathrm{C}$, respectively, which were achieved by, respectively, injecting $\mathrm{L}_{2} \mathrm{~N}$ and blowing hot air directly over the specimen faces for 15 minutes.

\subsection{Permanent indentation height (PIH)}

$\mathrm{PIH}$ corresponds to the maximum permanent deformation of the specimen after impact. Its determination was carried out by measuring the indentation height with the help of Digimess $^{\mathrm{TM}}$ vernier caliper with precision of $0.01 \mathrm{~mm}$.

\subsection{Micro X-ray computed tomography (mXCT)}

Impacted test pieces were scanned in a Brukker ${ }^{\mathrm{TM}}$ CT Scanner model Skyscan 1272. Xrays were generated by a Mo target, using voltage and current of, respectively, $100 \mathrm{kV}$ and $100 \mu \mathrm{A}$. Image acquisition was performed with an effective voxel size of $10 \mu \mathrm{m}$ for an exposure time of 4.6 seconds. 1 mm-thick $\mathrm{Cu}$ filter was used to collect a series of 1,012 projections in each case. Data visualization and processing was performed with PerGeos ${ }^{\mathrm{TM}}$ software. The segmentation strategy was based on manual seeding, by selecting the internal region of the sample through the Interactive Overlay Threshold (IOT) tool. First, a median filter was applied to the greyscale images to remove the noise from the data, followed by the application of the Marker-Based Watershed (MBW) and Separate Objects (SO) procedures to segment the region inside the sample from the outside.

\subsection{Cross-section microscopy (CSM)}

Following mXCT examination, Glare ${ }^{\mathrm{TM}}$ specimens were cross-sectioned at the impacted region and examined using AxionCam ${ }^{\mathrm{TM}}$ Model ICc 5 reflected light microscope (RLM) and Inspect $^{\mathrm{TM}} \mathrm{F} 50$ scanning electron microscope (SEM) to characterize internal damage and failure modes. The surfaces were platinum-coated previously to SEM inspection.

\subsection{Transmission electron microscopy (TEM)}

Thin 2024-T3 Al-alloy laminae were prepared by manual grinding the samples to a thickness of approximately $60 \mu \mathrm{m}$, followed by polishing them in Gatan ${ }^{\mathrm{TM}}$ Model 691 precision ion polishing system (PIPS). The microstructure was characterized by analyzing the distribution, morphology and chemical composition (EDS technique) of second phases in the grain interior and boundary. TEM images were obtained via Tecnai ${ }^{\mathrm{TM}}$ G2 F20 microscope operating at a voltage of $200 \mathrm{KV}$.

\subsection{Nanohardness (NHAR)}


Using the same specimens inspected by RLM and SEM, NHAR measurements were performed via Nanovea ${ }^{\mathrm{TM}}$ Model $\mathrm{Pb} 1000$ nanohardness equipment operating with Berkovich's geometry indentator. $20 \mathrm{mN}$ load was employed during indentation, each one lasting 6 minutes.

\subsection{Three-point flexural testing (3PF)}

Full-thickness rectangular specimens with in-plane dimensions of 50 x $50 \mathrm{~mm}^{2}$ were subjected to quasi-static bending displacement-control test conditions to determining initial stiffness and ultimate strength in $\mathrm{L}_{2} \mathrm{~N}$ environment. Loading/unloading cycles were applied in Instron-EMIC universal testing machine with $1 \mathrm{kN}$ full scale load cell. Load-train speed was 1 $\mathrm{mm} / \mathrm{min}$., and an adapted clip-gage was attached to the moving loading roller and a steady point in the test fixture between the bottom spans, so that load-line displacement could be accurately measured.

\section{RESULTS AND DISCUSSION}

\subsection{TSC damage}

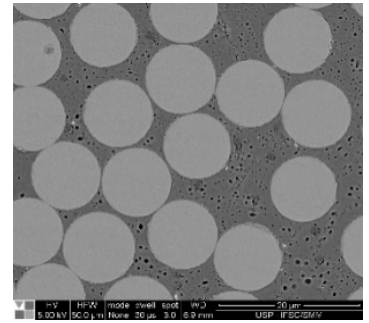

(a)

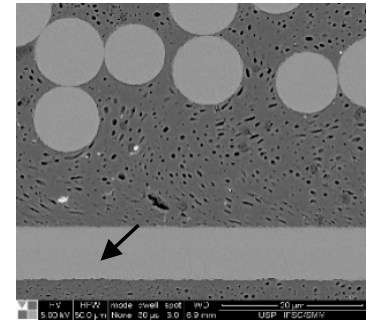

(b)

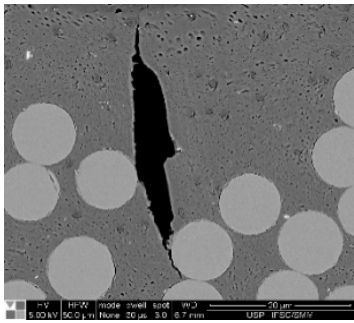

(c)

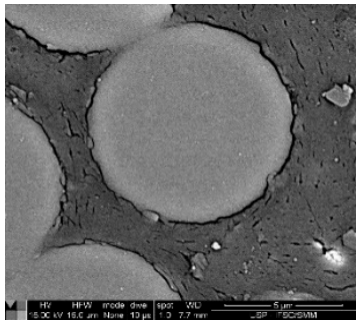

(d)

Figure 1. SEM micrographs of Glare: virgin (a,b), and TSC (c,d) conditions.

Figure 1 displays SEM micrographs related to Glare ${ }^{\mathrm{TM}}$ in both pristine and after TSC treatment. While the first condition presents numerous, though very small resin matrix microvoids (Fig. 1a,b), the TSC sample exhibits very large matrix cracks (Fig. 1c) besides extensive fiber / matrix debonding (Fig. 1d). Transversal matrix cracking seems to originate in the fiber / matrix interphase (arrowed) by thermal fatigue, since the inorganic and organic phases have substantially different thermal expansion/contraction coefficients.

\subsection{TG and FTIR}

According to Figure 2a the beginning of thermal degradation is higher for the TSC glass fiber-reinforced epoxy resin composite core as compared to the pristine condition. This strongly indicates that resin crosslinking took place during the aging treatment, much probably a post-cure effect due to the $+100{ }^{\circ} \mathrm{C}$ reversals.

Figure 2b shows less intense peaks associated to epoxy groups (bands between 950 and $860 \mathrm{~cm}^{-1}$ ) for TSC condition when compared to the pristine one. This signalizes the consumption of epoxy groups during the post-cure conditioning (section 3.1 above) and/or the result from water (boiling water during TSC) reaction with epoxy. The first hypothesis is more reliable, not only due to the results provided in item 3.1, but also owing to the decrease of transmittance signal related to hydroxyl $\left(\mathrm{OH}^{-}\right)$groups for the TSC treatment (peaks between 3600 and $3400 \mathrm{~cm}^{-1}$ ). 


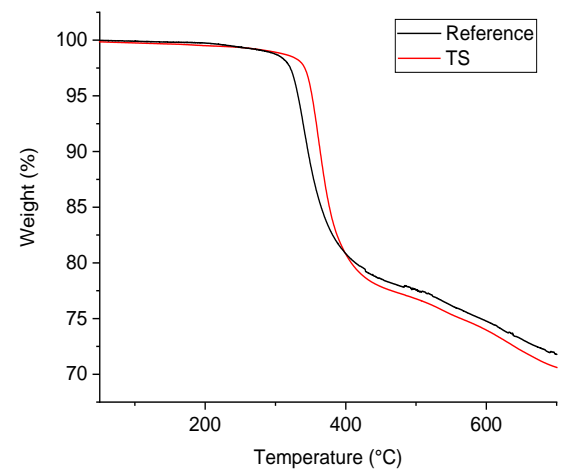

(a)

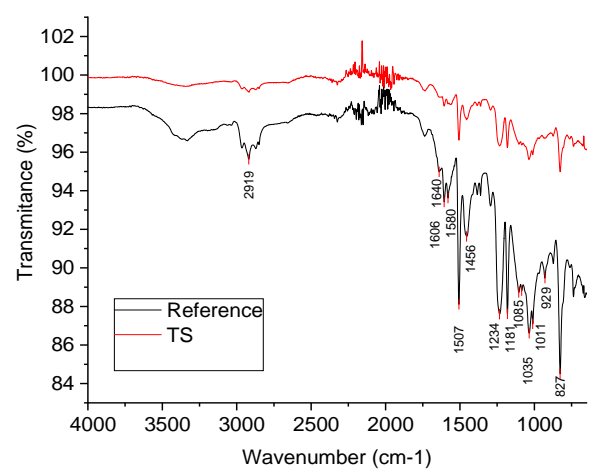

(b)

Figure. 2: TG (a) and FTIR (b) analyses of Glare's core composite.

\subsection{DMA}

DMA results plotted in Figure 3 show a significant increase of elastic modulus (E') for TSC laminate when compared to the virgin material. The augment of crosslinking density during the thermal conditioning (sections 3.1 and 3.2 above) is likely to have incremented this property [9]. Thermal hardening of 2024-T3 Al-alloy of Glare laminate due to TSC preconditioning cannot though be discarded [10].

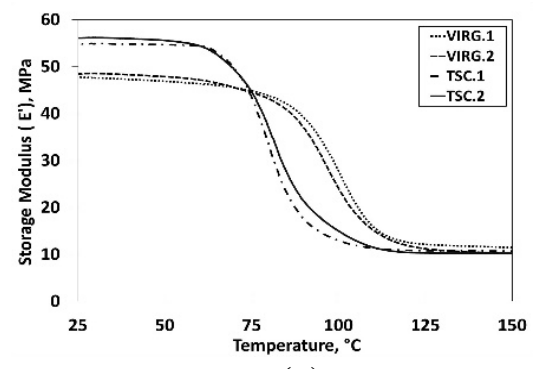

(a)

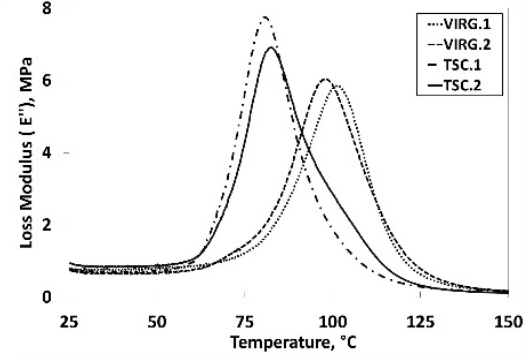

(b)

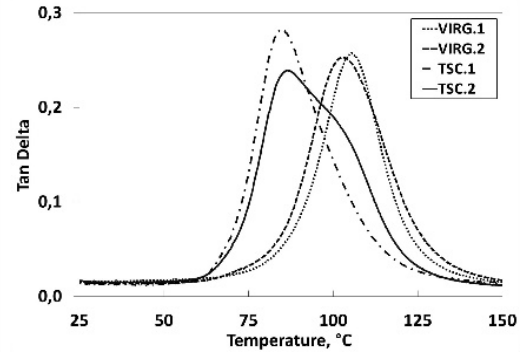

(c)

Figure 3. DMA analysis of Glare's core composite: (a) E', (b) E", (c) Tan $\delta$.

It is also remarkable the decrease in the glass transition temperature $\left(\mathrm{T}_{\mathrm{g}}\right)$ due to TSC treatment. Furthermore, an increase in the loss factor $(\tan \delta)$ peak is noted. It is well-known that, in polymers, this effect is related to plasticity and mobility of macromolecule chains; however, according to [11] in FRP this outcome may result from stress relaxation caused by physical-chemical degradation of fiber / matrix interface. It is worth emphasizing that the lack of $\mathrm{OH}^{-}$groups in the FTIR analysis in principle excludes the possibility of resin plasticization by water [12].

\subsection{PIH and mXCT}

The absorbed energy during ballistic impact is assumed to be proportional to the deformation of Glare beyond its global elastic regime, when, besides the outer Al-alloy sheets the FRP core can also be damaged (e.g., delamination, fiber breakage, matrix cracking, and so on). PIH values reflect this energy absorption capacity and are plotted in Figure 4(a). As expected, pristine test pieces impacted at $+100{ }^{\circ} \mathrm{C}$ (HOT condition) exhibit higher indentation heights when compared to coupons tested at $-196{ }^{\circ} \mathrm{C}$. Moreover, TSC decreases substantially the ability of Glare to deform permanently for both HOT and COLD impact conditions. 


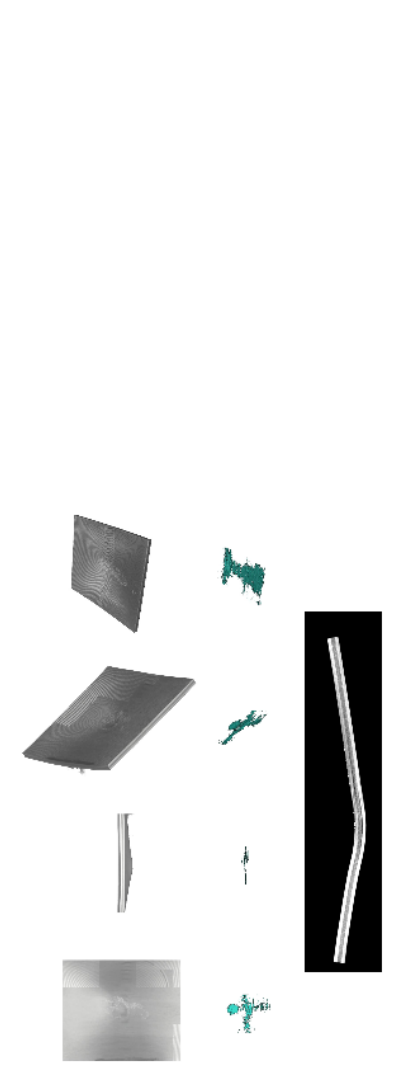

(b)
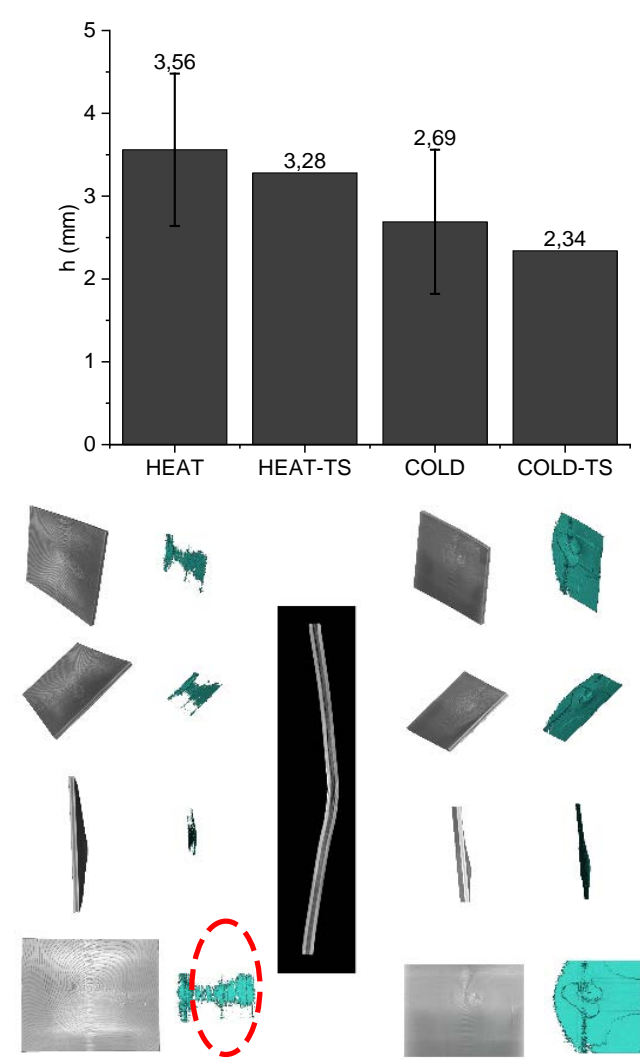

(c)

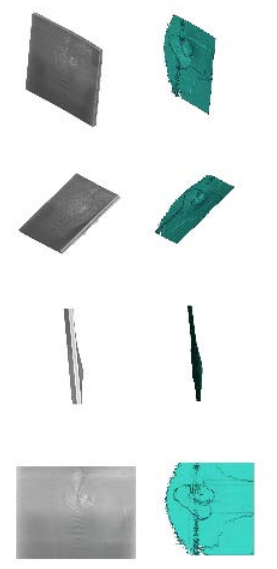

(d)

(a)

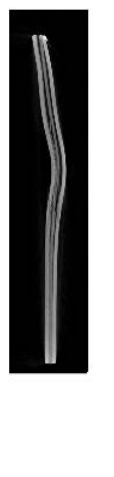

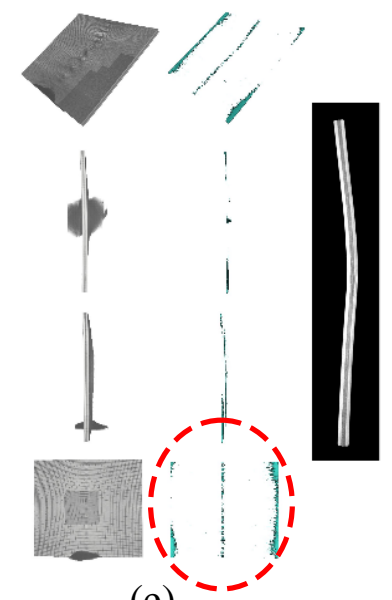

(e)

Figure 4. (a) PIH values for Glare ${ }^{\mathrm{TM}}$ hybrid laminate in four different combinations of thermal conditioning treatments and ballistic impact testing. Internal and external impact damages developed in Glare, according five mXCT views: (b) Virgin HOT, (c) TSC HOT, (d) Virgin COLD, (e) TSC COLD.

Regarding to mXCT results in Figure 4(b-e), TSC treatment does not seem to increase delamination growth substantially when the material is impacted at $100{ }^{\circ} \mathrm{C}$. It is worth mentioning that dashed red ellipses in Figures 4(c,e) include solely noise signals, which are indeed X-R imaging artifacts. This behavior is likely to result from energy absorption essentially taken place in the outer 2024-T3 Al-alloy sheets of Glare, probably favored by matrix cracking and fiber-matrix debonding, as observed in TSC micrographs (later in this text).

On the other hand, virgin test pieces impacted under cryogenic conditions exhibit outstanding volume of voids (i.e. delaminations) extending almost all over the specimen's internal interfacial planes, whereas the TSC test coupon is surprisingly virtually absent of this kind of damage. This behavior may be explained by simultaneous phenomena like cryogenic hardening of polymer matrix, which is further enhanced by post-curing the laminate, better fiber / matrix interaction and, consequently, higher debonding resistance resulting from compressive residual strength in cryogenically treated composites, $\mathrm{Al}$-alloy hardening due to precipitation aging at the time of TSC treatment. Besides, the thermal coefficient of shrinkage / expansion of the three phases present in Glare (ceramic fibers, epoxy resin and metal sheets) are determinant to establish the improvement of resin / fibers interplay. In this regard, since the resin matrix shrink more than the glass fibers, fiber compression and corresponding increase on fiber / matrix friction imply in improved toughening / strengthening mechanisms (e.g., fiber pull-out), not to mention the enhancement of the resin matrix resistance to cracking [9,10,13-20]. During impact at $-196{ }^{\circ} \mathrm{C}$ (COLD condition) these effects are apparently improved, while at $+100{ }^{\circ} \mathrm{C}$ (HOT) stress relaxation can take place overriding this, in 
principle, beneficial effect. Nevertheless, the TSC effect in the 2024-T3 Al-alloy sheets of Glare (items 3.3 and 3.4 above) and the consequences of ballistic impact temperature (HOT and COLD) in this material cannot be overlooked. This point will be returned later in this text.

\subsection{CSM}

Figure 5 presents optical microscopy views of impacted Glare laminate. Delamination at the metal / composite and composite laminae interfaces is the main damage mechanism detected. The extraordinary delamination resistance of TSC test coupon impacted under cryogenic temperature becomes evident as firstly detected via mXCT technique (section 3.4 above).

\subsection{TEM}

Figure 6 shows TEM microstructures of 2024 Al-alloy before (Fig. 6a) and after (6b) 1,200 thermal shock cycles. In the former condition it is possible to observe evenly distributed rodlike precipitates or $\mathrm{T}$ phases $\left(\mathrm{Al}_{20} \mathrm{Cu}_{2} \mathrm{Mn}_{3}\right)$ [21] in the grain interior, with no occurrence in the grain boundaries, whereas in the latter one needle like precipitates or $S$ ' phases $\left(\mathrm{Al}_{2} \mathrm{CuMg}\right)$ are also noted in both grain interior and boundaries, which the authors inferred to enhance Al-alloys' hardness [22].

\subsection{NHAR}

Figure 7 presents nanohardness results of virgin and TSC conditions of Glare ${ }^{\mathrm{TM}}$ laminate. One can notice that TSC treatment gave rise to a harder microstructure as compared to the pristine condition, thus confirming previous results provided in [22].

\subsection{PF}

Figure 8 displays some results obtained in three-point flexural testing, where is possible to conclude that the elastic modulus (stiffness) and ultimate strength of Glare ${ }^{\mathrm{TM}}$ in TSC condition are substantially higher than the pristine hybrid laminate. These figures confirm previous inference based on sections 3.6 and 3.7.
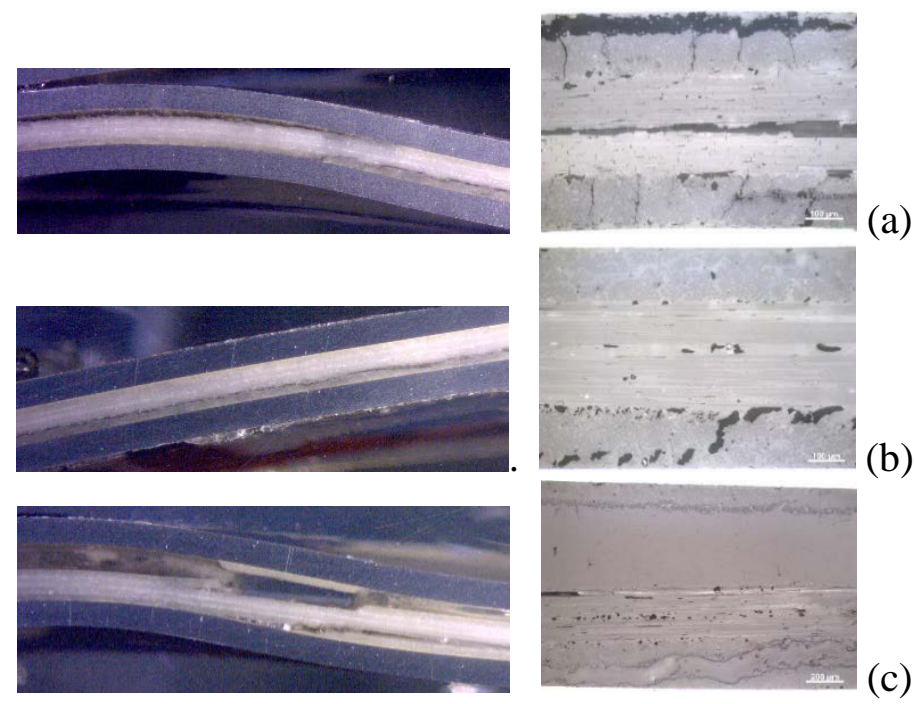

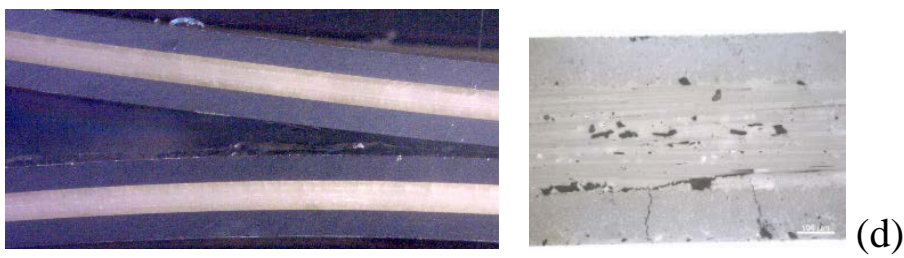

Figure 5. Optical micrographs of impact damaged Glare specimens: (a) Virgin HOT, (b) TSC HOT, (c) Virgin COLD, (d) TSC COLD.

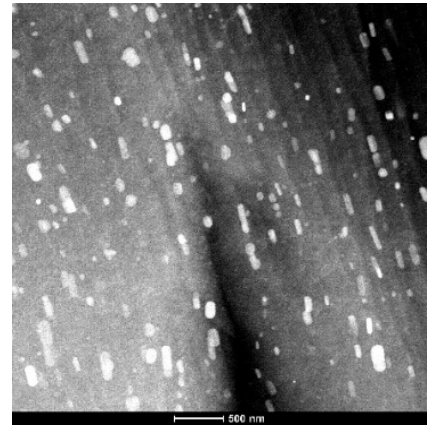

(a)

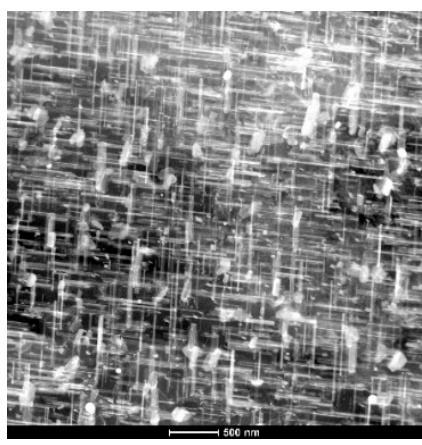

(b)

Figure 6. TEM images of virgin (a) and TSC (b) Glare ${ }^{\mathrm{TM}}$ hybrid laminate (Dark Field).

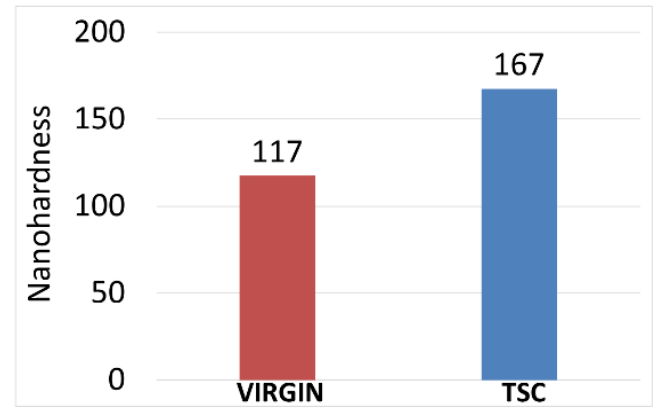

(a)

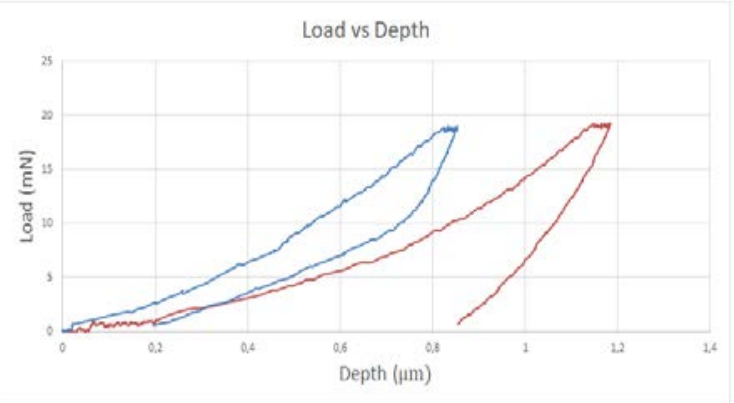

(b)

Figure 7. Nanohardness results of Glare ${ }^{\mathrm{TM}}$ in pristine and TSC conditions: (a) Bar plot; (b) Corresponding load-depth curves.

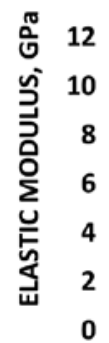

0

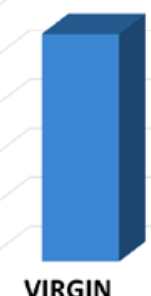

(a)

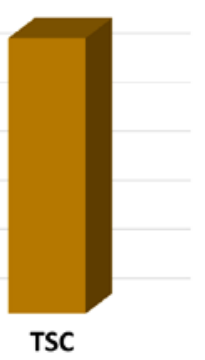

TSC

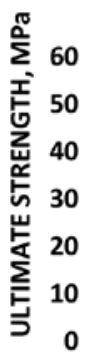

0

Figure 8. Stiffness (a) and ultimate strength (b) of Glare ${ }^{\mathrm{TM}}$ in pristine and TSc conditions.

\section{CONCLUSIONS}

Despite thermal shock cycling under extreme temperatures (from -196 to $+100{ }^{\circ} \mathrm{C}$ ) led to higher resistance to externally visible damage after ballistic impact of Glare ${ }^{\mathrm{TM}}$ fiber-metal laminate, as compared to the pristine hybrid material, in very high and very low temperature test, internal failure mechanisms have shown that specimens submitted to cryogenic impact after repeated thermal shock cycling presented the best impact resistance.Age hardening of outer 2024-T3 Al-alloy sheets, besides residual thermal stresses in the core glass fiber- 
reinforced epoxy matrix, as well as post-cure of the latter were identified as the major responsible for the observe results.

Acknowlegments: To Ferreira A., Andreeta M., Bonagamba T. from Instituto de Física de Sao Carlos (IFSC), Brazil.

\section{REFERENCES}

[1] Sinke J. Development of fibre metal laminates: concurrent multi-scale modeling and testing. Journal of Materials Science, v.41, p.6777-6788, 2006. DOI: 10.1007/s10853-0060206-5

[2] Vlot A., Gunnink J.W. Fibre metal laminatesKluwer Academic Publishers, Dordrecht, The Netherlands, 2001. ISBN 978-94-010-0995-9

[3] Vlot A. Glare: history of the development of a new aircraft material. Kluwer Academic Publishers, Dordrecht, The Netherlands, 2001. ISBN: 978-1-4020-0124-6, DOI: 10.1007/0306-48398-X

[4] Alderliesten R.C. Fatigue and fracture of fibre metal laminates. Springer, Dordrecht, 2017. ISBN: 978-3-319-56227-8

[5] George P.E., Dursch H.W. Low-earth orbit effects on organic composite materials flown on LDEF. NASA - Marshall Space Flight Center, Document Identification: 19940026531, p. 335-354, 1993.

[6] Han J-H., Kim C-G. Low earth orbit space environment simulation and its effects on graphite/epoxy composites. Composite Structures, v.72, p.218-226, 2006. DOI: 10.1016/j.compstruct.2004.11.007

[7] Katz S., Grossman E. Space environment effects on polymer matrix composites, John Wiley \& Sons, New Jersey, 2012. DOI: 10.1002/9781118097298.weoc228

[8] Yang B., Yue Z., Geng X. Effects of space environment temperature on the mechanical properties of carbon fiber/bismaleimide composites laminates. Proceedings of the Institution of Mechanical Engineers - Part G: Journal of Aerospace Engineering, v.232, p.3-16. DOI: $10.1177 / 0954410017740382$

[9] Gao Y., Yang D., He S., Li Z. Effect of vacuum thermocycling on properties of unidirectional m40j/ag-80 composites. In: Kleiman J.I. (eds). Protection of materials and structures from the space environment. space technology proceedings, vol 6, p.209-215. Springer, Dordrecht, 2006. DOI: 10.1007/1-4020-4319-8_19

[10] Pavan K.M, Sachin L.S. Mayur S., Chandrashekar A., Ajaykumar B.S. Effect of cryogenic treatment on the mechanical and microstructural properties of aluminium alloys - a brief study. International Journal of Mechanical and Production Engineering, v.2, p.95-99, 2014.

[11] Harris B., Braddell O., Almond D. Study of carbon fibre surface treatments by dynamic mechanical analysis. Journal of Materials Science, v.28, p.3353-3366, 1993. DOI: 10.1007/BF00354259

[12] Moy P., Karasz F.E. The interactions of water with epoxy resins. In: ACS Symposium Series, Chapter 30 Water in Polymers, v.127, p.505-513, 1980. DOI: 10.1021/bk-19800127.ch030

[13] Souza, c. S. R. De et al. Estudo do comportamento térmico de laminados carbono/epóxi submetidos a múltiplos ciclos térmicos. Polímeros, v.26, p.8-15, 2016. DOI: 10.1590/01041428.1769

[14] Ma H.L., Jia Z., Lau K., Leng J. Impact properties of glass fiber/epoxy composites at cryogenic environment. Composites Part B: Engineering, v.92, p.210-217, 2016.

[15] Park S.Y., Choi H.S., Choi W.J., Kwon H. Effect of vacuum thermal cyclic exposures on unidirectional carbon fiber/epoxy composites for low earth orbit space applications. Composites Part B: Engineering, v.43, p.726-738, 2012. 10.1016/j.compositesb.2011.03.007 
[16] Wang J., Xue X., Yang Z., Zhang H., Zhou Y. Effect of cryogenic treatments on mechanical properties of 2A11 aluminum alloy. Advanced Materials Research, v.146-147, p.1646-1650, 2010. DOI: 10.4028/www.scientific.net/AMR.146-147.1646

[17] Kumar M.S., Sharma N., Ray B.C. Mechanical behavior of glass/epoxy composites at liquid nitrogen temperature. Journal of Reinforced Plastics and Composites, v.27, p.937-944, 2008. DOI: $10.1177 / 0731684407085877$

[18] Indumathi J., Bijwe J., Ghosh A.K., Fahim M., Krishnaraj N. Wear of cryo-treated engineering polymers and composites. Wear, v.225229, p.343-353, 1999. DOI: 10.1016/S0043-1648(99)00063-0

[19] Anashkin O.P., Keilin V.E., Patrikeev V.M. Cryogenic vacuum tight adhesive. Cryogenics, v.39, p.795-798, 1999. DOI: 10.1016/S0011-2275(99)00089-2

[20] Kasen M.B. Mechanical and thermal properties of filamentary-reinforced structural composites at cryogenic temperatures 1: glass-reinforced composites. Cryogenics, v.15, p.327-349, 1975. DOI: 10.1016/0011-2275(75)90079-X

[21] Lv P., Zhang Z., Wang X., Ji L., Hou X., Guan Q. Microstructure evolution of 2024 and 7A09 aluminium alloys subjected to thermal cycling in simulated LEO space environment. Materials Research Innovations, v.18, p.169-175, 2014. DOI: 10.1179/1433075X13Y.0000000182

[22] Garay-Reyes C.G., González-Rodelas L., Cuadros-Lugo E., Martínez-Franco E., Aguilar-Santillan J., Estrada-Guel I., Maldonado-Orozco M.C., Martínez-Sánchez R. Evaluation of hardness and precipitation in Zn-modified Al2024alloy after plastic deformation and heat treatments. Journal of Alloys and Compounds, v.705, p.1-8, 2017. DOI: 10.1016/j.jallcom.2017.02.111 